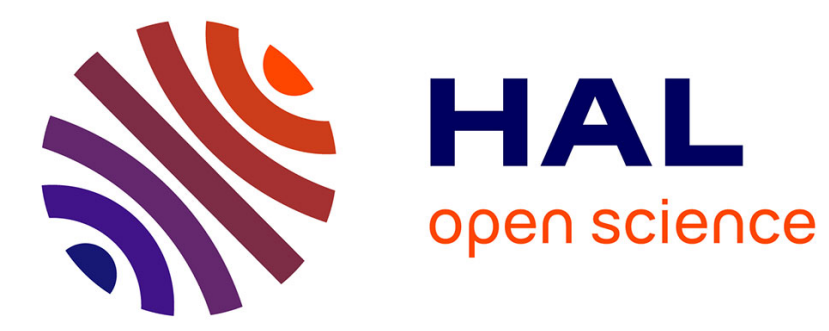

\title{
Multi-instrumentation of very high temperature tests
}

\author{
Thibaut Archer, Pierre Beauchêne, Myriam Berny, François Hild
}

\section{To cite this version:}

Thibaut Archer, Pierre Beauchêne, Myriam Berny, François Hild. Multi-instrumentation of very high temperature tests. SEM Annual Conference and Exposition on Experimental and Applied Mechanics, 2018, Jun 2018, Greenville, United States. 10.1007/978-3-319-95074-7_14 . hal-02632540

\section{HAL Id: hal-02632540 \\ https://hal.science/hal-02632540}

Submitted on 27 May 2020

HAL is a multi-disciplinary open access archive for the deposit and dissemination of scientific research documents, whether they are published or not. The documents may come from teaching and research institutions in France or abroad, or from public or private research centers.
L'archive ouverte pluridisciplinaire HAL, est destinée au dépôt et à la diffusion de documents scientifiques de niveau recherche, publiés ou non, émanant des établissements d'enseignement et de recherche français ou étrangers, des laboratoires publics ou privés. 


\title{
Multi-instrumentation of very high temperature tests
}

\author{
T. Archer ${ }^{1,2,3}$, P. Beauchêne ${ }^{1}$, M. Berny ${ }^{2,3}$, F. Hild ${ }^{2}$ \\ 1: Office National d'Etudes et de Recherches Aérospatiales (ONERA), France \\ 2: Laboratoire de Mécanique et Technologie (LMT), ENS Paris-Saclay, France
}

3: SAFRAN, Safran Ceramics, France

\begin{abstract}
For the use of thermal and environmental barrier coating (T/EBC) with ceramic matrix composite it is crucial to understand the behavior under extreme environments representative of the hot sections of turbine engines. An experimental setup to simulate such thermal loading has been developed with various instrumentation enabling for kinematic and temperature field measurements.
\end{abstract}

Key Words: Environmental barrier coating, ceramic matrix composite, infrared thermography, digital image correlation, heat haze effect.

\section{Introduction}

Ceramic matrix composites (CMCs) are currently considered as an attractive option for use in the hot sections of next generation turbine engines. Their high temperature mechanical and physical properties and their low density could provide increased performance under such extreme environments. Among the CMCs developed today, silicon carbide (SiC) fiberreinforced melt-infiltrated (MI) SiC matrices have shown good stability up to $1300^{\circ} \mathrm{C}$ [1], especially against high temperature oxidation in dry air. However, for applications in turbine engines like blades or shroud, the presence of water vapor leads to surface recession of the protective silica layer formed at high temperatures [2]. It is therefore essential to protect the CMC against operating temperatures but also corrosive environments, which calls for the development of new thermal and environmental barrier coatings (T/EBCs).

In order to successfully develop T/EBC-CMC systems, the understanding of the behavior of T/EBC under representative stresses, temperatures and corrosive atmospheres is essential. Given the environment, these components will face high thermal gradients due to high heat fluxes and forced air cooling resulting in complex thermomechanical stress states.

The differences between isothermal and thermal gradient conditions [3] make standard tests used for characterization illadapted to assess damage initiation and growth. For that reason a test rig has been developed to examine T/EBC-CMC systems (Figure 1). 


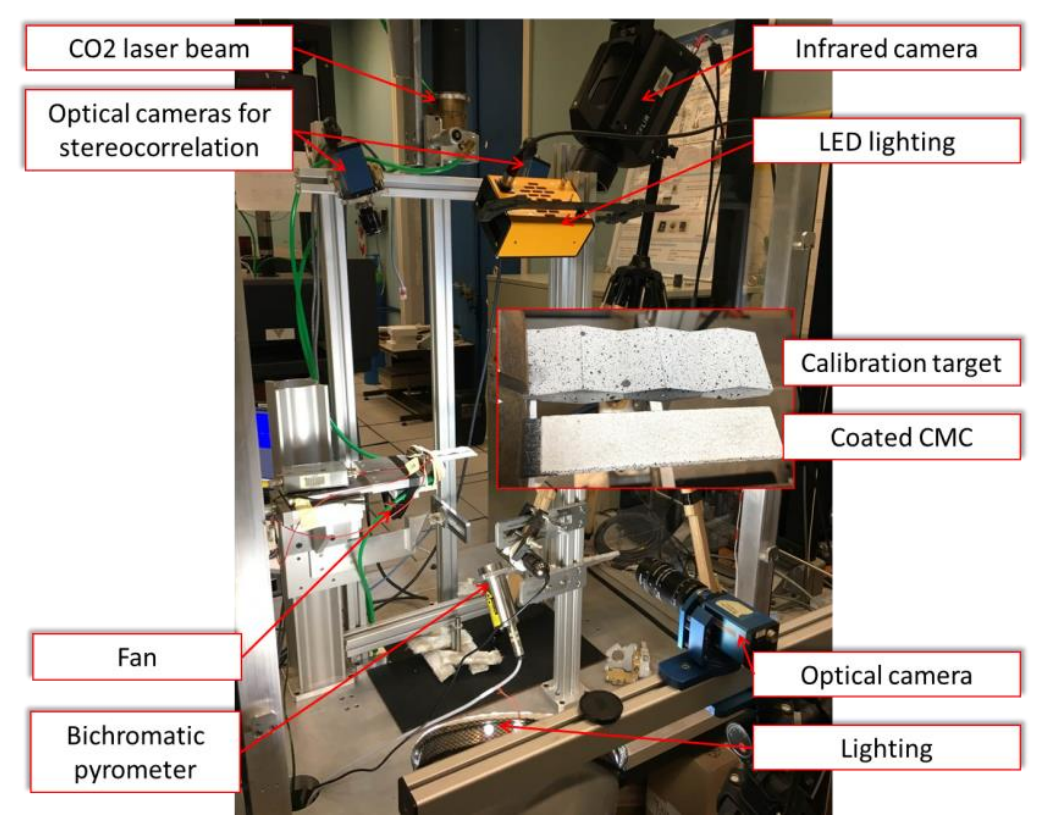

Fig. 1 High heat flux laser test using visible light and infrared cameras

\section{Experimental setup and tested materials}

A high power $(2 \mathrm{~kW})$ high heat flux CO2 laser heats locally the sample, thereby generating multi-axial (in-plane and throughthickness) thermal gradients. Under such conditions, the material expands and deflects. To measure the thermomechanical fields of the sample, the top surface is monitored using a middle-wave infrared (IR) camera (FLIR X6580sc) to measure temperature fields, a pair of optical cameras (AVT Pike-421 with 2.8/50 lenses) and an LED lighting (7700 Lumen) to measure 3D surface displacement fields. The back side is monitored using bichromatic (IGAR6, Lumasens) and monochromatic (MI3, Raytek) pyrometers. An additional optical camera (AVT Pike-421 with 4/80 lens and 41 mm extension ring) is positioned to measure the edge motion of the sample.

The tested sample consists of a woven CMC manufactured with Hi-Nicalon S SiC fiber and $\mathrm{SiC}$ matrix. The substrate is then coated with a thin layer of bond coat, and finally with an environmental barrier coating.

\section{Full-field measurements}

Given the complex manufacturing process of T/EBC, the knowledge of thermomechanical properties is often complicated and expensive when the material undergoes heat-treatments that produce physical and/or structural changes.

During high temperature tests, an accurate measurement of temperature and displacement fields will allow in-situ estimations of key thermomechanical parameters such as the thermal expansion coefficient and Young's modulus, which play a critical role in the thermomechanical behavior of T/EBC-CMC systems. Therefore, for the monitoring of such tests, a specific instrumentation needs to be implemented.

IR thermography is performed with a middle wave infrared camera $[3 \mu \mathrm{m} ; 5 \mu \mathrm{m}]$ with a band-pass filter at $4 \mu \mathrm{m}$. It is sensitive to a radiant flux coming from the thermal scene, which is converted into digital levels (DL) and then with the emissivity into temperature. The advantage of a monochromatic camera is that the radiant flux can be expressed with Planck's emission law. Given the large range of temperatures during laser heating and the change of emissivity $\in$ as a function of the temperature, the rebuilt of the temperature field with a constant emissivity induces errors (Figure 2). Using a low emissivity will overestimate low temperatures, when using a high emissivity will largely underestimate high temperatures. 


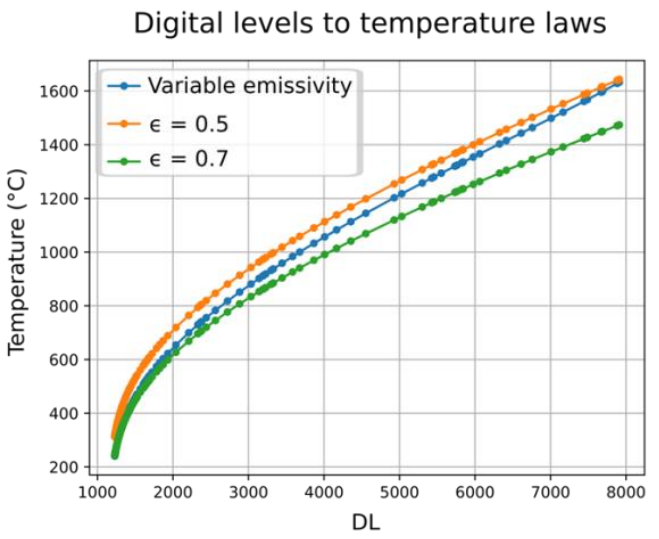

(a)

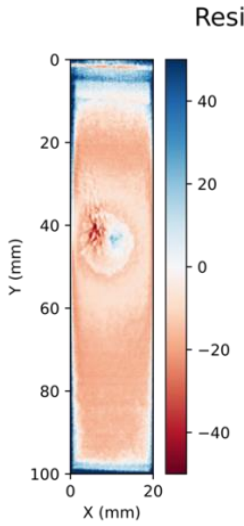

(b)

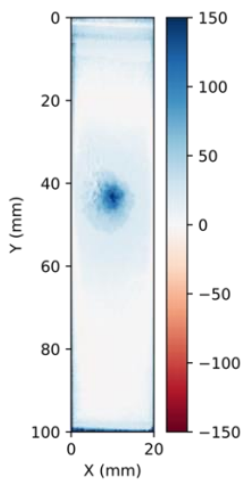

(c)

Fig. 2 (a) temperature calibration laws, residue between field rebuilt with variable emissivity and constant emissivity (b) $\in=0.5$ and (c) $\in=0.7$

Under such thermal loadings, the system expands and deflects. One of the biggest challenges is to measure very low displacement levels (a few tens of micrometers). For the use of stereocorrelation, a high temperature speckle pattern was created using SiC powder. A fan was used to reduce heat haze effects and lower the uncertainties. Visible light images were post-processed using the commercial software VIC 3D (Correlated Solutions). Results of 10 pictures taken every $10 \mathrm{~s}$ from a stabilized temperature step are compared with and with no fan (Figure 3). The white zone at the center of the image corresponds to the laser beam (i.e., the highest temperatures) where the pixels of the optical camera are saturated. In the present case, the use of a fan is critical in reducing the biases induce by the heat haze.

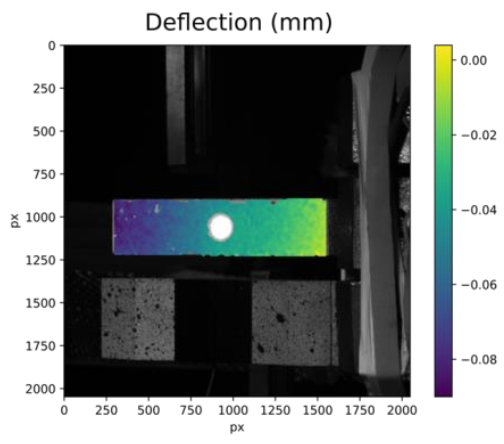

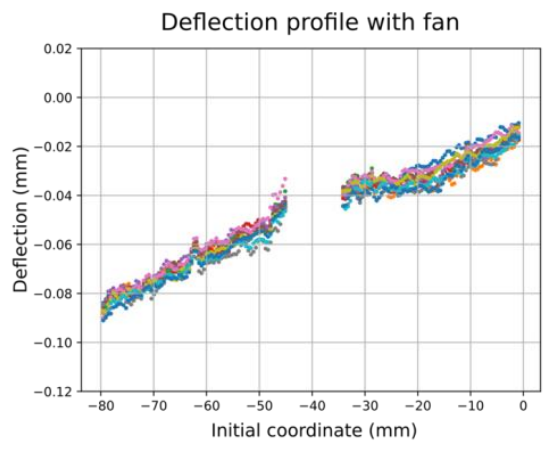

(a)

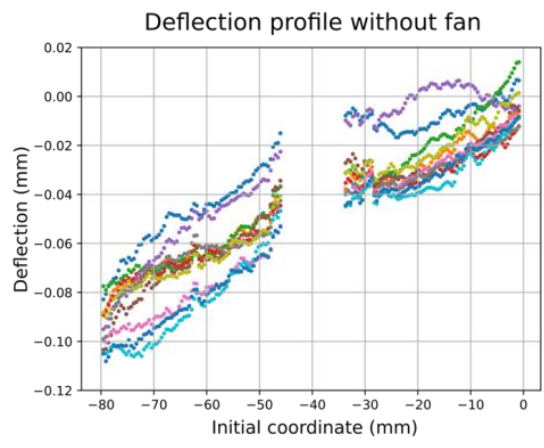

(b)

Fig. 3 Out of plane measurement (a) with fan (b) with no fan

This work was supported under PRC MECACOMP, French research project co-funded by DGAC and SAFRAN Group, piloted by SAFRAN Group and involving SAFRAN Group, ONERA and CNRS.

\section{References}

[1] JA DiCarlo, H-M Yun, GN Morscher, and RT Bhatt. SiC/SiC composites for $1200^{\circ} \mathrm{C}$ and above. Handbook of Ceramic Composites, pages 77-98, 2005.

[2] KL More, PF Tortorelli, LR Walker, N Miriyala, JR Price, and M Roode. High temperature stability of SiC-based composites in high-water-vapor-pressure environments. Journal of the American Ceramic Society, 86(8):1272-1281, 2003.

[3] Y Tan, JP Longtin, S Sampath, and D Zhu. Temperature-gradient effects in thermal barrier coatings: An investigation through modeling, high heat flux test, and embedded sensor. Journal of the American Ceramic Society, 93(10):3418-3426, 2010. 